\title{
FAMÍLIA E ESCOLA NA CONTEMPORANEIDADE: FENÔMENO SOCIAL
}

\author{
Marcia Cristina Argenti PEREZ ${ }^{1}$
}

\begin{abstract}
RESUMO: Esta pesquisa tem como objetivo compreender a dinâmica das práticas educativas desenvolvidas nas famílias de camadas populares e na instituição escolar e a influência que ambas exercem na aprendizagem de crianças do ensino fundamental. Para a realização de tal propósito, este estudo analisa a dinâmica da relação família-escola; as representações de pais, professores e alunos sobre o processo de escolarização; a organização do processo de ensino-aprendizagem, a avaliação do rendimento escolar; o enfrentamento das questões relacionadas à diversidade socioeconômica e cultural das crianças; as manifestações de acompanhamento dos educadores aos alunos com dificuldade de aprendizagem e aos alunos com bom rendimento escolar; as expectativas do educando sobre sua experiência escolar; as iniciativas de superação das dificuldades escolares da criança pela escola e pela família. A pesquisa foi realizada em uma escola pública de ensino fundamental, na cidade de Bauru/SP, que atende crianças provenientes de famílias das camadas populares. Como procedimentos metodológico utilizamos algumas técnicas de pesquisa: questionário, entrevista semi-estruturada, observação participante na escola durante o ano letivo, algumas visitas às famílias, e coleta de registros escolares. A análise qualitativa dos dados indica alguns fatores para a condição de sucesso ou fracasso escolar dos alunos das camadas populares, como a forma de envolvimento da família na trajetória escolar dos filhos, o papel dos professores no incentivo à aprendizagem e o empenho do educando na superação das dificuldades para a concretização de seus projetos escolares. Conclui-se que, dependendo do incentivo da escola e da família nas atividades escolares, os alunos modificam o desempenho de forma positiva quando há um intenso acompanhamento das duas instituições ou de modo insatisfatório quando o aluno não é incentivado a melhorar seu rendimento.
\end{abstract}

PALAVRAS CHAVE: Família. Escola. Desempenho escolar.

As atuações da família e da escola sofrem influências das determinações do contexto histórico-social (CECCON; OLIVEIRA; OLIVEIRA, 1997; NÓVOA 1998; NOGUEIRA; CATANI, 1999; CANDAU, 2000). Podemos afirmar que as práticas educativas da família e da escola, bem como as representações sobre elas, refletem o contexto social em que estão inseridas (PEREZ, 2000, 2004).

Nas sociedades ocidentais, são inúmeras e diversas as agências de socialização por meio das quais os indivíduos têm acesso aos conteúdos culturais, como a família, a escola, as instituições religiosas, os meios de comunicação de massa etc. No entanto, as influências que os indivíduos

\footnotetext{
${ }^{1}$ UNESP - Universidade Estadual Paulista. Faculdade de Ciências - Departamento de Educação. Bauru - SP - Brasil. 17033-360 - mcaperez@fc.unesp.br
} 
recebem das agências socializadoras são diferenciadas, dependendo da inserção desses indivíduos e dos agentes socializadores em determinada camada ou classe social (VICENTE, 1998).

Todavia, mesmo considerando que a classe social determina, em grande medida, as condições de socialização e de educação (BOURDIEU; PASSERON, 1982; D’AVILLA, 1998; STEHR, 2000), é importante não utilizarmos esse argumento como o único para a compreensão das instituições educativas, uma vez que é preciso considerar os aspectos particulares do processo de ensino-aprendizagem. Não podemos deixar de lado o conhecimento da história de vida pessoal e ocupacional dos membros na família, as dinâmicas presentes nas relações cotidianas no ambiente escolar, as representações que os sujeitos têm do mundo e de suas condições de existência. Cada membro da família de um determinado grupo social, mesmo apresentando uma representação social comum ao grupo, introjeta uma significação dessa representação que lhe é particular, com especificidades e aspectos que só lhe dizem respeito e significado (BERGER; LUCKMANN, 1985).

No tocante à família, esta se constitui como uma unidade de reprodução social e biológica e uma instância de cooperação econômica e de consumo de bens materiais e simbólicos e, simultaneamente, um espaço da expressão das emoções, sejam elas de afeto ou agressão, de segurança ou rivalidade (DURHAM, 1983).

A família representa o espaço de transmissão dos padrões sociais, seja por meio do cotidiano e das trocas de experiências, seja por meio das práticas de socialização e educação das gerações mais novas. Porém, o grupo familiar não reproduz, apenas, o instituído, ele pode atuar como criador de oposições, inovações e questionamentos de normas e valores (ROMANELLI, 1997).

Segundo as pesquisas de Perez (2000, 2004) é comum ouvirmos que o grupo familiar, atualmente, está em crise e, até mesmo, se extingüindo. Na verdade, o que vem ocorrendo são mudanças na estrutura e nos papéis dos membros da família, em decorrência das alterações sociais que, por sua vez, acabam colaborando para a existência de diversas formas de constituição e modalidades de educação familiar, negando a construção histórica de um modelo de família único e ideal. Por família, atualmente, podemos entender uma série de arranjos nas relações entre pessoas ligadas por laços de aliança e afinidade.

A idealização de um modelo ideal de família fortalece o discurso preconceituoso que desqualifica os grupos que não apresentam a constituição familiar nuclear. A conseqüência desse discurso é o de justificar qualquer dificuldade dos membros dos grupos com constituições diferenciadas 
em função da diversidade de arranjos, ou sejam passam a ser identificados como, famílias desestruturadas (GOLDANI, 2002; PEREZ, 2004).

O que caracteriza a família contemporânea é o fato dela se constituir como uma unidade social formada por diversos arranjos familiares, mas com finalidades e objetivos semelhantes. Dentre algumas constituições familiares temos: família nuclear, constituída pelo pai, mãe e filho(s); família ampliada, em que além do núcleo familiar, outros parentes agregam-se ao grupo; famílias recompostas que são resultados de uma segunda união de um ou ambos os cônjuges; famílias matrifocais, na qual as mães chefiam o grupo doméstico sozinhas ou com o auxílio de outros parentes; famílias patrifocais, em que o pai é o responsável pelos filhos, agregado ou não a outros parentes (DURHAM, 1983).

No atual contexto, quando pensamos na função socializadora da família temos claro várias finalidades que são a ela atribuídas, como a transmissão de alguns aspectos culturais básicos, relacionados à forma de linguagem, aos costumes, valores, padrões de comportamento etc. Espera-se, também, que ela contribua para o desenvolvimento e formação da personalidade e identidade das gerações mais novas (COLL; PALÁCIOS; MARCHESI, 1995; LAGO, 1998; KALOUSTIAN, 1998; PEREZ, 2000).

A escola é, junto com o grupo familiar, uma agência social que exerce influência no desenvolvimento e nas aprendizagens da criança. Porém, a influência da escola deve ser compreendida à luz de sua evolução histórica, da qual emergiu como instituição destinada a instruir os educandos das classes sociais privilegiadas sendo, portanto, por um longo período, restrita a poucos. É com o processo de modernização da sociedade capitalista que a instituição escolar se torna acessível para a formação da população em geral. No entanto, a educação escolar, mesmo com a democratização do acesso ao ensino, sempre foi diferenciada entre os segmentos sociais, pois, para as classes dominantes, a escola é considerada um meio de formação intelectual e acadêmica. Já para as camadas populares, a escola é vista como um meio de qualificação para o trabalho e de ascensão social (CUNHA, 1996; D’AVILLA, 1998; MONTOVANINI, 1999).

A escola é vista como uma instituição especializada na formação e na educação das gerações mais novas, cujo surgimento se dá em razão do desenvolvimento da sociedade, bem como da intensificação da divisão do trabalho. A escola mostra-se como instrumento de educação diferenciado das formas básicas existentes, como, por exemplo, a família e a comunidade que se caracterizam pela fragmentação e assistematização de suas práticas. 
A instituição escolar apresenta-se com o intuito de produzir e reproduzir uma homogeneidade cultural relacionada com a divisão do trabalho, sendo parcialmente determinada por conflitos sociais e por relações de dominação. Os grupos dominantes desempenham uma forte influência nas orientações das instituições escolares, no que se refere à seleção dos conteúdos, à constituição dos currículos, às práticas educativas como, também, no direcionamento de privilégios a públicos determinados (NOGUEIRA, 1998a; NOGUEIRA; ROMANELLI; ZAGO, 1998).

Na perspectiva da Psicologia do Desenvolvimento, admite-se que no período dos primeiros anos escolares, a criança desenvolve e familiariza-se com tarefas intelectuais, estratégia de memorização, diversificação na organização das operações mentais, evolui no conhecimento interpessoal e social, incorpora noções de raciocínio e comportamento moral. A aquisição de novos conhecimentos na escola possibilita uma reorganização cognitiva que determina, em grande medida, a atuação dos indivíduos, permitindo-lhes compreender e resolver adequadamente os problemas por eles enfrentados. Esse mesmo processo torna a criança progressivamente mais consciente de suas capacidades e limitações cognitivas, adquirindo paulatinamente maior controle e planejamento de sua atividade, fruto da inserção social e comunicativa com os adultos (COLL; PALÁCIOS; MACHERSI, 1995).

Ao analisarmos a educação da criança na família e na escola é possível arrolarmos algumas diferenciações que a bibliografia relata (GOMES, 1993; TERRAIL, 1997; NOGUEIRA, 1998b; PEREZ, 2000, 2004; ZAGO, 2003) quanto às práticas educativas que cada uma dessas instituições exerce. Dentre elas, podemos mencionar que na família as práticas educativas são desenvolvidas no cotidiano, ao passo que na escola configura-se uma intensa programação de práticas e atividades educativas, elaboradas segundo diretrizes educacionais planejadas a priori. As práticas educativas exercidas no ambiente familiar produzem resultados rápidos no comportamento do educando. Já a transmissão de conhecimento no âmbito escolar engloba uma preparação para a realidade futura do aluno. A aprendizagem da criança na instituição familiar se faz na relação com os membros do grupo doméstico. No tocante à escola essa aprendizagem envolve momentos programados, com pessoas específicas (professores, grupo da sala de aula, funcionários).

Assim sendo a instituição escolar e familiar constituindo-se como agências educativas e socializadoras apresentam tanto pontos em comum quanto diferentes, ou seja, compartilham de procedimentos para preparar o educando no desenvolvimento de habilidades que contribuam para uma 
participação crítica na sociedade, diferenciam-se nas atividades de ensino, já que a escola tem como responsabilidade ensinar os conteúdos escolares valorizados e considerados essências para a instrução de novas gerações e às famílias cabem as funções relacionadas às orientações sociais, morais, afetivas, isto pelo menos no plano do ideal.

A bibliografia especializada (GOMES, 1996; SZYMANSKI, 1997; PEREZ, 2000, 2004; PARO, 2000) enfatiza que nas relações família-escola existem descontinuidades intrínsecas nas estratégias e nos recursos comunicativos, nos conteúdos, na organização e nas exigências da escola e que se diferenciam das que vivenciam nas experiências com o grupo familiar. Todavia, dependendo da relação de continuidade e descontinuidade entre família-escola, podem existir referenciais que facilitem as aprendizagens cognitivas e sociais da criança, como também podem criar uma espécie de abismo intransponível que condiciona negativamente a adaptação e o êxito no meio escolar.

A instituição escolar acaba incorporando atribuições específicas de todo um contexto histórico-social que lhe impõe finalidades e exigências, além de determinar a condução da transmissão de conhecimentos relevantes. Contudo, de acordo com as considerações de Petitat (1994), a escola colabora não só para reproduzir aspectos de desigualdades e diferenças entre os indivíduos, seja pela classe social, raça, situação econômica, cultural, política ou religiosa, mas também ao estabelecer suas finalidades, pode promover inovações para a sociedade.

Em relação à escolarização nas famílias de camadas populares, há um consenso entre a maioria dos pesquisadores (LAHIRE, 1995; VIANA, 1998; PEREZ, 2000, 2004; SIGOLO; LOLLATO, 2001), de que estas valorizam, embora de modos diferenciados, a educação escolar dos filhos. Gomes (1996) ressalta a importância atribuída à escola por essas famílias como garantia de um futuro melhor para os filhos. No entanto, aponta que após alguns anos de investimento na escolarização dos filhos, a desesperança parece se abater sobre esse investimento. As dificuldades escolares, aliadas à grande necessidade de a criança das camadas populares ocupar-se com o trabalho precoce para ajudar no sustento do grupo familiar, dificulta a freqüência escolar.

Embora a educação básica seja um direito de todos os cidadãos, as barreiras enfrentadas pelas populações desfavorecidas econômica e socialmente tornam a escolarização um sonho distante de ser concretizado. Uma coisa é garantir o acesso à escola, outra é oferecer condições de manutenção para os educandos terem regularidade e aproveitamento escolar eficiente. 
Verificamos o quanto a escola tem enfrentado dificuldades em aceitar as mudanças sociais e familiares e considerá-las nas novas exigências que elas trazem na execução dos objetivos escolares. De acordo com Nogueira (1998a) não podemos deixar de considerar que muitos pais sentemse inseguros e incapacitados de planejarem o processo educacional de seus filhos, e acabam atribuindo à escola a função de complementar a formação do educando enquanto o investimento familiar restringe-se à manutenção da permanência da criança na instituição escolar. Todavia essa compulsoriedade muitas vezes é pouco considerada pela escola, principalmente porque os professores aproveitam-se das incertezas dos pais e da valorização da função educativa da escola, para desenvolverem um mecanismo de defesa, considerando que as falhas do sistema escolar devem-se à desestruturação da família já que os professores, muitas vezes incorporam representações “distorcidas” das famílias dos alunos (PERRENOUD, 2000).

Alguns estudos (PARO, 2000; CLANDININ; CONNELLY, 2005) acerca da influência da família na escolarização dos filhos têm apontado a importância da relação família-escola e a necessidade de amenização dos conflitos entre essas duas instituições educativas. Algumas medidas de aproximação, em muitos casos, estão voltadas para a diminuição da distância entre família e escola, e geralmente se fundamentam na postura e nas concepções presentes nos educadores da instituição escolar. Assim, a influência dos pais na escola pode assumir diferentes dimensões dependendo da ênfase dos objetivos que subsidiam as ações das escolas, como por exemplo, aspectos financeiros, administrativos ou pedagógicos.

Ao analisar a dinâmica escolar, a pesquisa de Perez (2004) denuncia que é possível verificar que o professor é o elemento chave, aquele que dá vida ao processo de ensino-aprendizagem e, portanto, das práticas escolares, inclusive aquelas relacionadas à relação família-escola. Sua postura, suas representações e conhecimentos determinam em parte o que fazem no contato com os educandos e, de modo correlato, com seus familiares. Desse modo, o profissional da educação desenvolve sua prática com base em percepções e análises sobre os resultados da sua postura pedagógica, que por sua vez, dependem do contexto em que atua.

Dentre alguns exemplos dessas tentativas de direcionamento da escola em incentivar a participação dos pais na escola, podemos destacar, a organização do Conselho da Escola, os Parâmetros Curriculares Nacionais, o Dia da Família na Escola, o Projeto Escola da Família e a iniciativa da participação de voluntários. Essas propostas sugerem a ampliação da presença da comunidade nas 
escolas e estimula a amenização do "abismo” entre essas agências, incentivando o exercício de papéis parentais mais ativos nos processos de escolarização dos filhos. Em casos de atuações pedagógicas inadequadas alguns estudos (PATTO, 1992; PEREZ, 2000, 2004; SIGOLO; LOLLATO, 2001) denunciam que os docentes atribuem as causas das dificuldades e dos conflitos escolares à realidade familiar vivenciadas pelos alunos, em que o estereotipo de "família desestruturada" domina as causas externas que justificam o desempenho escolar dos alunos.

Aparentemente, as orientações do sistema educacional procuram valorizar a relação com as famílias dos alunos buscando incentivar o empenho familiar na escolarização dos filhos. Todavia um problema que pode estar ocorrendo no exercício da relação família-escola é a maneira adotada em que a instituição escolar estabelece uma aproximação unidirecional com o grupo familiar, procurando-os somente quando o educando apresenta problemas disciplinares ou de aprendizagem. Acredita-se que os professores supõem que é de responsabilidade da família resolver os problemas escolares de seus filhos. Nesse contexto quando a intervenção familiar não consegue resultados positivos, os professores geralmente ressaltam que as famílias dos alunos são desinteressadas e negligentes no acompanhamento da escolarização dos filhos (PEREZ, 2004).

Essa representação preconceituosa limita a compreensão da dinâmica da instituição familiar das camadas populares, já que o estereotipo de família ideal supostamente coesa e engendrada das camadas médias é contraposto ao estereotipo de famílias desestruturada da população pobre, o que acentua e hierarquiza as diferenças sociais, culturais e econômicas. Ao argumentar sobre o alcance da educação, nas diferentes esferas sociais, Perez (2004) alerta que a desigualdade de acesso à educação escolar já começa antes do acesso à instituição de ensino:

Além da singularidade do papel educativo da escola e da família ainda não estar plenamente definido, pelo menos no que envolve as relações que estabelecem entre si, outros problemas enfrentados nesse processo podem ser percebidos. Entre eles estão a diferença na comunicação estabelecida entre pais e professores; o medo dos professores em não exercer a autoridade e confrontarse com a desvalorização de sua atuação profissional, a rotina escolar que não estimula a presença participativa dos pais, com exceção de momentos pontuais, como é o caso das reuniões escolares entre pais e professores; a resistência dos pais em envolverem-se com a escola em função de sua condição sociocultural ou pelas situações de cupabilização que sempre enfrentam nos contatos com a instituição (PEREZ, 2004). 
A partir desse panorama dos resultados da presente pesquisa realizada em com pais, professores e alunos da primeira fase do Ensino Fundamental de uma escola pública no município de Bauru/SP, podemos verificar o quanto a escola apresenta dificuldades em oferecer uma comunicação que estimule a relação família-escola, criando um espaço de acolhimento dos pais, de modo que eles possam se sentir aceitos, conhecer o trabalho realizado e a forma com que podem contribuir para esta tarefa sem que tenham que se tornar os professores particulares dos filhos fora do espaço escolar, corroborando com algumas pesquisas (GOMES, 1993; PEREZ, 2000, 2004; PARO, 2000) denunciam o quanto os professores solicitam dos pais um acompanhamento que constitui-se na atuação da família na realização de atividades de reforço do conteúdo trabalhado no ambiente escolar. Essa cobrança de ensino escolar na família, causa enormes injustiças, visto que muitos pais não tem disponibilidade e muito menos conhecimento para assumir essa responsabilidade.

A leitura de alguns estudos (PATTO, 1990; SERBINO; GRANDE, 1994; LAHIRE, 1997) acerca da problemática da situação de fracasso escolar de alunos das séries iniciais de escolarização mostra a necessidade da compreensão das diversas interferências nas relações do educando com o processo de ensino-aprendizagem. No universo da pesquisa percebemos que as interferências mais expressivas nesse processo e na condição de fracasso escolar, estão relacionadas a problemas individuais do educando, tais como imaturidade, desinteresse e desmotivação pelo ensino, falta de habilidades específicas, ritmo pessoal diferente do grupo, problemas orgânicos, ocorrência de desnutrição ou deficiências; dificuldades no contexto familiar, relacionadas com problemas emocionais, econômicos, culturais ou sociais, mas além desses problemas, há outros relacionados ao do próprio âmbito escolar, como a inadequação da postura, concepções e representações do processo de ensino-aprendizagem pelos professores, dificuldade e despreparo para a tomada de decisões metodológicas e avaliativas, desconhecimento da realidade, das dificuldades e do potencial de seus próprios alunos.

Patto (1990) apresentou uma profunda revisão dos estudos especializados que denunciam que a questão do fracasso escolar não é um fenômeno contemporâneo, já que desde os anos 30 até os anos 90 os elevados índices de fracasso escolar decorrentes da incidência de evasão e reprovação escolar nos primeiros anos da escola pública brasileira, são acompanhados do discurso de políticas educacionais que defendiam a melhoria das condições educacionais, que em sua maioria não foram efetivadas na prática escolar. 
Estudos pedagógicos (SCHWARZ, 1973; PATTO, 1990, 1992) descrevem as causas do fracasso escolar no cenário educacional brasileiro. Na virada para o século XX, surgiram explicações de cunho médico e com fundamentos racistas. A partir de 1930 até meados dos anos setenta, a teoria da carência ou deficiência cultural tecia argumentos que atribuíam as causas dos problemas educacionais à criança, entendendo-a como portadora de atraso no desenvolvimento psicomotor, na percepção, cognição, afetividade, e que eram próprios das crianças das camadas populares. Nos primeiros anos da década de 1970 até recentemente, predominam afirmações relacionadas à teoria da diferença cultural, localizando as origens do fracasso escolar na dificuldade da criança e de seu grupo familiar. No final da década de 1980 e nos primeiros anos da década de 1990 o enfoque é modificado, e defende-se que as condições do sistema escolar é que tem contribuído para a condição da produção do fracasso escolar.

Pesquisas de Carraher, D. Carraher e Schliemann (1982), Patto (1990), Lahire (1995, 1997), Aquino (1997), Stehr (2000) e Zago (2003) denunciam o fracasso escolar e apontam que são principalmente as crianças das camadas populares que fracassam na escola e acabam interrompendo os estudos. Desse modo, além do fracasso da criança, existe o fracasso da família que, na maioria das vezes, fez vários sacrifícios para contribuir para a escolaridade dos filhos.

Diversos estudos (PATTO, 1990; GOMES, 1996; CECCON; OLIVEIRA; OLIVEIRA, 1997; KALOUSTIAN, 1998; NOGUEIRA, 1998a, 1998b; FERRARO, 2000) apontam que as crianças das camadas populares e das camadas médias ingressam na escola, apresentando um acervo cultural divergente e com expectativas diferenciadas quanto à escolarização. Além disso, trazem para a esfera escolar suas representações do mundo, que são frutos do contexto social e das experiências já vivenciadas. Por sua vez, as pesquisas denunciam que é comum os educadores transferirem, em suas práticas pedagógicas, uma visão idealizada, segundo os padrões das camadas sociais privilegiadas, do que seja o aluno, sua família e o processo de aprendizagem. Os professores acabam utilizando padrões idealizados que não são compatíveis com a realidade pessoal e cultural da maioria de seus educandos.

O resultado dessa inadequação reflete-se nos altos índices de fracasso escolar, logo no início do processo de escolarização. Essa questão traduz o despreparo de muitos professores ao enfrentarem a diversidade sociocultural de seus alunos, transferindo, como um mecanismo de defesa, as justificativas das dificuldades escolares, tanto para a criança quanto para seu grupo familiar.

Inúmeras pesquisas (PATTO, 1990; GOMES, 1993; LAHIRE, 1997; MONTOVANINI, 1999; PEREZ, 2000, 2004; LOVISOLO, 2005) ressaltam que a escola acaba culpabilizando o próprio 
aluno e seu grupo familiar pelos resultados escolares negativos. A escola não vem conseguindo trabalhar e administrar a diversidade cultural e econômica de seus alunos.

No entanto, é importante não reduzirmos nossas reflexões com argumentos deterministas que atribuem o fracasso escolar apenas aos alunos provenientes de famílias das classes populares. É evidente que, nessas classes, as dificuldades são mais expressivas; no entanto, a escolarização das crianças dos meios populares não pode ser compreendida como algo inatingível.

Ao enfocarmos a instituição escolar, precisamos não esquecer que ela é parte da sociedade em que vivemos, na qual ocorrem transformações permeadas por crises econômicas e políticas, pela intensificação das desigualdades sociais, pela existência de programas sociais marcados por um forte assistencialismo. Nesse plano, dificilmente a instituição escolar consegue se organizar no sentido de promover uma atualização e adequação do seu ensino às necessidades de seus educandos.

Pontuamos na pesquisa que tanto o sucesso quanto o fracasso escolar, dependem de vários fatores relacionados ao próprio educando, a seu meio familiar e ao sistema escolar, no que diz respeito à seleção dos conteúdos, às formas de avaliação, à qualidade e eficiência do ensino, à adequação da escola à diversidade socioeconômica e cultural de seus alunos, etc.

Estudos sobre sucesso/fracasso escolar (LAHIRE, 1995, 1997; VIANA, 1998; ZÉROULOU, 2005) mostram que em camadas privilegiadas econômica e socialmente existem casos de fracasso escolar, apesar de todo o investimento financeiro nos estudos das crianças. Por outro lado, alguns estudos descrevem várias histórias de crianças provenientes de camadas populares que vivem uma situação de sucesso escolar, apesar de todas as carências de seu meio familiar. Assim sendo, a existência de capital cultural relevante em um grupo familiar não garante que esse capital será transmitido de forma adequada e plena aos educandos desse grupo. E, desse modo, comprova a tese de que as dificuldades escolares não se constituem como característica presente apenas nas trajetórias das crianças das camadas populares.

Ao longo dos anos, a questão do fracasso escolar já foi atribuída à criança, à família, à escola, ao processo de ensino-aprendizagem. Sendo assim encontrar a causa do insucesso escolar, direcionando a culpa em algum dos agentes envolvidos no processo educativo, é uma posição ingênua e limitada, já que se deixa de analisar cada contexto de uma maneira mais critica e abrangente, desconsiderando-se, principalmente os fatores políticos e filosóficos que constituem a educação em um dado momento social e cultural de uma sociedade. Visto que é do conhecimento da população em 
geral, e não apenas dos professores, a insuficiência de verbas direcionadas a educação, as precárias condições estruturais (espaço físico, materiais pedagógicos, inovações tecnológicas), administrativas (profissionais preparadas para planejar e conduzir uma proposta pedagógica de acordo com as necessidades dos educandos) e pedagógicas (professores competentes que mobilizem habilidades para realizar propor um ensino planejado, diversificado, pautado no respeito ao ritmo dos alunos e na constante avaliação e reflexão do processo educativo) das escolas públicas, a desvalorização e as limitações da formação e atuação docente, além de muitos outros problemas. Desse modo, é incontestável a necessidade da educação brasileira avaliar a implantação das políticas educacionais e os alcances de reformas que possibilitem reais melhorias no ensino escolar.

O fracasso escolar, na maioria das vezes é visto como um problema próprio de cada aluno. No entanto, não podemos responsabilizar somente à ele, nem, tão pouco ao professor, que geralmente não está preparado para a função de avaliar o processo de aprendizagem, visto a ênfase na avaliação formativa, representada, principalmente pelas provas, que categorizam o desempenho dos alunos. Acreditamos sobretudo, na necessidade de revisão dos paradigmas da avaliação do desempenho escolar, bem como da educação como um todo, para que a aprendizagem do aluno possa ir além das notas e menções e sim representar conhecimentos significativas para a formação e desenvolvimento global do educando.

Tendo em vista o estudo apresentado é necessário rever a concepção de avaliação, e mais do que isso rever inclusive as concepções de ensino, aprendizagem, conteúdos escolares, finalidades da educação. Impõe refletir na urgência de um projeto pedagógico fundamentado em valores e ideais comprometidos com o exercício da cidadania. Somente após essa imensa revolução é que a educação poderia auxiliar na transformação da realidade, colaborando para a amenização das desigualdades, para a valorização da diversidade de princípios, comportamentos, ritmos, interesses, vontades, motivações que o ser humano pode desenvolver e ser estimulado no convívio social, principalmente, nas relações entre as principais instituições educativas: Família e Escola. 


\title{
FAMILY AND SCHOOL IN CONTEMPORARY TIMES: SOCIAL PHENOMENON
}

\begin{abstract}
This research has as its objective to understand the dynamics of the educative practices developed by the popular classes families and by the school institutions and the influence both exert on the leaning process of children in the fundamental education. To carry on such a propose, this study analyses the dynamics of the family-school relationship; the representation of parents, teachers and students about the school process; the organization of the teaching-learning process; the evaluation of the scholar output; the facing of the questions related to the social, economical and cultural diversity of the children; the manifestations of the accompanying teachers to the students with learning difficulties and to the students with good scholar performance; the learner's expectations about his/her school experiences; the initiatives to overcome the child's school difficulties by the school and the parents. The research was carried out in a fundamental education public school in Bauru-SP, which attends children from popular classes. The methodological procedures employed were some research techniques: questionnaires, semi-structured interview, participative observation in the school during the academic year, some visits to the families and collection of school registers. The qualitative analysis of the data indicates some factors for the school success or failure of the popular classes children, as the kind of family involviment with their children's school trajectory, the teacher's role in the encouragement to the learning and the learner's commitment in the superation of difficulties and the realization of the school projects. One can conclude that depending on the school and family incentive in the school activities, the students modificate their performances in a positive way when there is an intensive accompaniment of both institutions or in an insatisfatory way when the student is not incentivated to improve his/her learning outputs.
\end{abstract}

KEYWORDS: Family. School. School output.

\section{REFERÊNCIAS}

AQUINO, J.G. Erro e fracasso na escola: alternativas teóricas e práticas. São Paulo: Summus, 1997.

BERGER, P.; LUCKMANN, T. A construção social da realidade. Petrópolis: Vozes, 1985.

BOURDIEU, P.; PASSERON, J.C. A reprodução: elementos para uma teoria do sistema de ensino. Rio de Janeiro: F. Alves, 1982.

CANDAU, V. M. F. Reinventar a escola. Rio de Janeiro: Vozes, 2000. 
CARRAHER, T. N.; CARRAHER, D. W.; SCHLIEMANN, A. D. Na vida dez, na escola zero: os contextos culturais de aprendizagem da matemática. Cadernos de Pesquisa, São Paulo, n.42, p.79-86, ago. 1982.

CECCON, C.; OLIVEIRA, M. D.; OLIVEIRA, R. D. A vida na escola e a escola na vida. Petrópolis: Vozes, 1997.

CLANDININ, D. J.; CONNELLY, F. M. Teacher's professional knowledge landscapes: teacherstories-stories of teacher's- school stories - stories of schools. Educational Researcher, Washington, v.25, n.3, 2005.

COLL, C.; PALÁCIOS, J.; MARCHESI, A. Desenvolvimento psicológico e educação. Porto Alegre: Artes Médicas, 1995. v.1.

CUNHA, M. V. A escola renovada e a família desaqualificada: do discurso histórico-sociológico ao psicologismo na educação. Revista Brasileira de Estudos Pedagógicos, Brasília, v.77, n.186, p.318345, maio/ago, 1996.

D’AVILLA, J. L. P. Trajetória escolar: investimento familiar e determinação de classe. Educação \& Sociedade, Campinas, Ano 19, n. 62, p.31-63, 1998.

DURHAM, E. R. Família e reprodução humana. In: DURHAM, E. R. et al. Perspectivas antropológicas da mulher. Rio de Janeiro: Zahar, 1983. p.15-43.

FERRARO, A. R. Diagnóstico da escolarização no Brasil. Revista Brasileira de Educação, São Paulo, n.12, p.22-47, 2000.

GOLDANI, A.M. As famílias brasileiras: mudanças e perspectivas. Cadernos de Pesquisa, São Paulo, n.91, p.7-23, 2002.

GOMES, J. V. Família, escola, trabalho: construindo desigualdades e identidades subalternas. 1996. Tese (Livre-Docência em Educação) - Faculdade de Educação, Universidade de São Paulo, São Paulo. 1996.

Relações família e escola - continuidade e descontinuidade no processo educativo. Idéias, São Paulo, n.16, p.84-90, 1993.

KALOUSTIAN, S. M. (Org.). Família brasileira: a base de tudo. São Paulo: Cortez, 1998. 
LAGO, M. C.de S. Famílias e modos de vida: gênero, gerações e identidade. Paidéia, Ribeirão Preto, v.8, n.14-15, p. 33-43, fev-ago. 1998.

LAHIRE, B. Sucesso escolar nos meios populares: as razões do improvável. São Paulo: Ática, 1997.

Tableaux de familles: heurs et malheurs scolaires em millieux populaires. Paris: Gallimard, 1995.

LOVISOLO, H. Escola e família: constelação imperfeita. Ciência e Cultura, São Paulo, v.6, n.31, p.52-56, 2005.

MANTOVANINI, M. C. L. O olhar do professor ao diagnosticar as dificuldades de aprendizagem: critérios e justificativas empregadas para a escolha de bons e maus alunos. 1999. Dissertação (Mestrado em Educação) - Faculdade de Educação, Universidade de São Paulo, São Paulo, 1999.

NOGUEIRA, M. A. A. A escolha do estabelecimento de ensino pelas famílias: a ação discreta da riqueza cultural. Anped - Revista Brasileira de Educação, São Paulo, n.7, p.42-56, 1998a.

Relação família-escola: novo objeto na sociologia da educação. Paidéia, Ribeirão Preto, v.8. n.14-15, p.91-103, fev.-ago, 1998b.

NOGUEIRA, M. A. A.; CATANI, A (Org.). Escritos de educação. Petrópolis: Vozes, 1999.

NOGUEIRA, M. A. A.; ROMANELLI, G.; ZAGO, N. (Org.).Família e escola: trajetórias de escolarização em camadas populares e médias. Petrópolis: Vozes, 2000.

NÓVOA, A. Relação escola-sociedade: novas respostas para velhos problemas. In: SERBINO, R. V. et al. Formação de professores. São Paulo: Ed. UNESP, 1998. p.19-39.

PARO, V.H. Qualidade do ensino: a contribuição dos pais. São Paulo: Xamã, 2000.

PATTO, M.H.S. A produção do fracasso escolar: histórias de submissão e rebeldia. São Paulo: T.Q. Queiroz Editor, 1990.

A família pobre e a escola pública: anotações sobre um desencontro. Psicologia USP, São

Paulo, v.3, n.1-2, p.107-121, 1992. 
PEREZ, M.C.A. Família e escola na educação da criança: análise das representações presentes em relatos de alunos, pais e professores de uma escola pública de ensino fundamental. 2000. Dissertação (Mestrado em Educação) - Faculdade de Educação, Universidade de São Paulo, São Paulo, 2000.

Práticas educativas da família e da escola e seus efeitos no desempenho escolar de crianças das camadas populares do ensino fundamental. 2004. Tese (Doutorado em Educação) Faculdade de Educação, Universidade de São Paulo, São Paulo, 2004.

PERRENOUD, P. 10 novas competências para ensinar. Porto Alegre: Artmed, 2000.

PETITAT, A. Produção da escola, produção da sociedade. Porto Alegre: Artes Médicas, 1994.

ROMANELLI, G. Famílias de classes populares: socialização e identidade masculina. Cadernos de Pesquisa - NEP, São Paulo, v.3, n.1-2, p.25-34, 1997.

SERBINO, R. V.; GRANDE, M. A. R. de (Org.). A escola e seus alunos: estudos sobre a diversidade cultural. São Paulo: Ed. UNESP, 1994.

SIGOLO, S. R. L.; LOLLATO, S.O Aproximações entre escola e família: um desafio para educadores. In: CHAKUR, C.R. de S.L. (Org.). Problemas da educação sob o olhar da psicologia. São Paulo:

Cultura Acadêmica, 2001.

STEHR, N. Da desigualdade de classe à desigualdade de conhecimento. Revista Brasileira de Ciências Sociais, São Paulo, v.15, n.42, p.101-112, fev. 2000.

SCHWARZ, R. As idéias fora do lugar. Estudos CEBRAP, São Paulo, v.3, p.151-61, 1973.

SZYMANSKI, H. Encontros e desencontros na relação família-escola. In: TOZZI, D. A.; ORNESTI, L. F. (Coord.). Os desafios enfrentados no cotidiano escolar. São Paulo: FDE, 1997.

TERRAIL, J. P. La sociologie dês interactions famile-école. Societés contemporaines, n.25, p.67-83, 1997.

VIANA, M. J. B. Longevidade escolar em famílias de camadas populares: algumas condições de possibilidade. 1998. Tese (Doutorado em Educação) - Faculdade de Educação, Universidade Federal de Minas Gerais, Belo Horizonte, 1998. 
VICENTE, C. M. O direito à convivência familiar e comunitária: uma política de manutenção do vínculo.In: KALOUSTIAN, S. M. (Org). Família brasileira: a base de tudo. São Paulo: Cortez, 1998. p.47-59.

ZAGO, N. Classes populares e a questão escolar: um estudo sobre as trajetórias de escolarização a nível de primeiro grau. In: REUNIÃO ANUAL DA ANPED, 16., 2003, Caxambu. Anais... Caxambu: ANPED, 2003.

Realidades sociais e escolares e dinâmica familiar nos meios populares. Paidéia, Ribeirão Preto, p.91-103, 1998.

ZÉROULOU, Z. La réussite scolaire des enfants d'immigres. Revue Française de Sociologie 2 v.29, p. 447-470, 2005. 